\title{
THE AMERICAN PEDIATRIC SOCIETY AND
}

\section{THE SOCIETY FOR PEDIATRIC RESEARCH}

\author{
Combined \\ Program and Abstracts \\ Washington Sheraton Hotel \\ Washington, D.C. \\ May 6-9, 1985
}

(Session listings and contents appear in chronological order) 